\title{
Chronic Alcohol Abuse-Induced Hypokalemia Might Lead to Delayed Diagnosis or Misdiagnosis of Thyrotoxic Periodic Paralysis
}

\author{
Yan-Yu Lin ${ }^{1}$, Yu-Shan Hsieh ${ }^{2}$ \\ 1. Division of Endocrinology and Metabolism, Department of Internal Medicine, Taipei Medical University Hospital, \\ Taipei, TWN 2. School of Nursing, National Taipei University of Nursing and Health Sciences, Taipei, TWN
}

Corresponding author: Yu-Shan Hsieh, 228455300teresa@gmail.com

\begin{abstract}
Thyrotoxic periodic paralysis is an uncommon and potentially life-threatening complication of thyrotoxicosis and hyperthyroidism characterized by acute and reversible episodes of muscle weakness and hypokalemia. Here is a 41-year-old Taiwanese male patient without any family history of hyperthyroidism presented to the emergency room of our institution with initial symptom of acute lower limb weakness. Laboratory analysis revealed uncommonly severe hypokalemia $(<1.5 \mathrm{mEq} / \mathrm{L})$. A thyroid function test revealed hyperthyroidism, and thyroid ultrasonography revealed findings compatible with Graves' disease. However, symptoms such as nausea, vomiting, diarrhea, and heavy breathing were absent. He was administered with $15 \mathrm{mg}$ of methimazole and $30 \mathrm{mg}$ of propranolol per day for complications of hyperthyroidism. Then we exhaustively evaluated the patient's history and lifestyle habits, and found that the patient had chronic alcohol abuse (an 1-L bottle $45 \%-48 \%$ liquor per week) for more than 10 years. In this case, chronic alcohol abuse may have increased the patient's tolerance to the profound hypokalemia such that it did not immediately show critical symptoms. Therefore, according to this case report, we suggest that chronic alcohol consumption or abuse may lead patients, especially those with hyperthyroidism, to ignore or delay treatment.
\end{abstract}

Review began 06/10/2021 Review ended 06/15/2021 Published 06/23/2021

\section{○ Copyright 2021}

Lin et al. This is an open access article distributed under the terms of the Creative Commons Attribution License CC-BY 4.0., which permits unrestricted use, distribution, and reproduction in any medium, provided the original author and source are credited.
Categories: Endocrinology/Diabetes/Metabolism, Emergency Medicine, Internal Medicine

Keywords: thyrotoxic periodic paralysis, alcohol abuse, hypokalemia, graves' disease, endocrine, case report

\section{Introduction}

Thyrotoxic periodic paralysis (TPP) is an uncommon and a potentially life-threatening complication of thyrotoxicosis, characterized by acute and reversible episodes of muscle weakness and hypokalemia. Although the incidence is only approximately $2 \%$ in patients with hyperthyroidism, and the symptoms of paralysis arise within a few hours [1], some cases of ventricular arrhythmia still have been reported [2]. Hence, early diagnosis and prompt treatment are important for avoiding complications and mortality. However, among causes of hypokalemia in patients with hyperthyroidism, alcohol consumption is one potential but usually ignored cause. Hypokalemia is commonly found in $50 \%$ patients with chronic alcoholism [3]. It is associated with an increased risk of arrhythmia in patients and as much as a 10-fold increase in all-cause mortality [4]. A previous study found that hypokalemia was more common in patients who abused alcohol than in a control population [5].

Therefore, chronic hypokalemia [6] and even other electrolyte disorders [7] can be observed in patients with alcoholism. Here, we present an interesting case of TPP in a Taiwanese male patient who also had a history of chronic alcohol abuse for almost 10 years. The patient presented with a sudden onset of weakness in the bilateral lower extremities and uncommonly severe profound hypokalemia.

\section{Case Presentation}

A 41-year-old Taiwanese male patient without any family history of hyperthyroidism presented to the emergency room of our institution with an initial symptom of acute limb weakness (level of muscle power is $2-3)$. Laboratory analysis revealed uncommonly severe hypokalemia $(<1.5 \mathrm{mEq} / \mathrm{L})$; the serum potassium level was not even detectable.

However, symptoms, such as nausea, vomiting, diarrhea, heavy breathing, and EKG changes, were absent.

There was no history of recent strenuous exercise, diuretic use, or other chronic disease, but the patient had chronic alcohol abuse (an 1-L bottle 45\%-48\% liquor per week) for more than 10 years. Other abnormal findings were observed: a thyroid function test (TFT) revealed hyperthyroidism with serum free thyroxine (fT4) level >6.60 ng/dL and a thyroid-stimulating hormone (TSH) level $0.06 \mathrm{mU} / \mathrm{L}$. The serum TSH receptor antibody binding percentage was high at $85.92 \%$, and thyroid ultrasonography findings were compatible with Graves' disease (Figure 1). These findings were consistent with Graves' disease as the etiology of his hyperthyroidism. 


\section{Cureus}

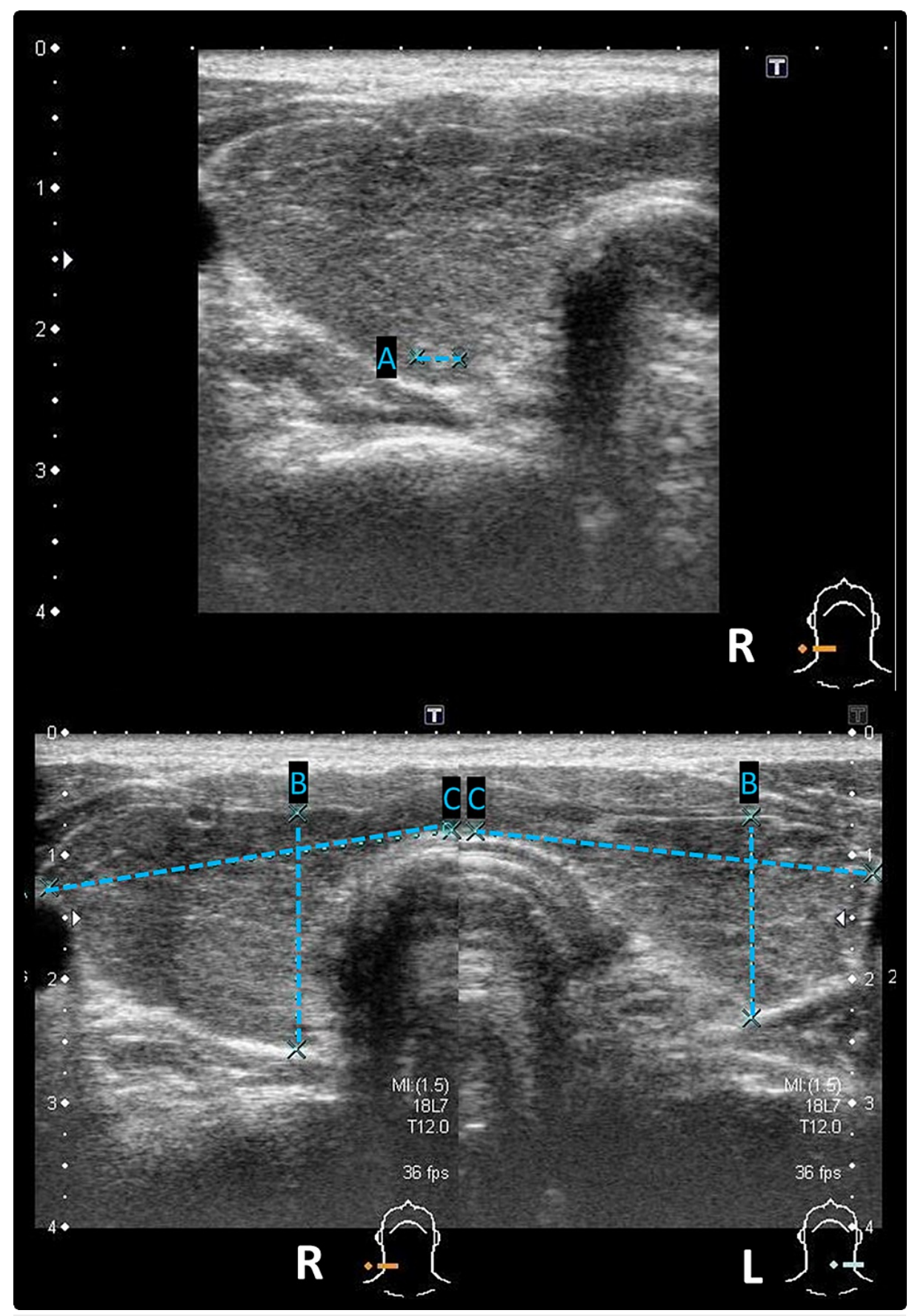

\section{FIGURE 1: Thyroid ultrasonography}

A: Compatible with Graves' disease. Right 1 nodule: $0.31 \mathrm{~cm}$; B, C: Size of thyroid, right side is $3.28 \times 1.91 \mathrm{~cm}$ and left side is $3.22 \times 1.62 \mathrm{~cm}$.

The results of other biochemical studies are shown in Table 1 . These showed profound electrolyte abnormalities such as hypokalemia. Due to the findings of severe hyperthyroidism and hypokalemia, he was admitted to the ICU for further care and he then received potassium replacement (potassium $10 \mathrm{mEq}$ ) acutely. He was administered $15 \mathrm{mg}$ of methimazole and $30 \mathrm{mg}$ of propranolol per day for complications due to hyperthyroidism. Following the treatment, the potassium level improved to $3.7 \mathrm{mEq} / \mathrm{L}$. One month after treatment, a follow-up TFT revealed a near-normal fT4 $(1.38 \mathrm{ng} / \mathrm{dL})$ without rebound hyperkalemia. No paralysis occurred, and the hyperthyroidism was well controlled with continued anti-thyroid drugs and $\beta$ blockers prescribed in the outpatient department.

\begin{tabular}{|l|l|l|l|l|l|l|}
\hline & Interval value (after & $\begin{array}{l}\text { Interval value } \\
\text { (after }\end{array}$ & $\begin{array}{l}\text { Interval value (after } \\
\text { anti-thyroid agent) }\end{array}$ & $\begin{array}{l}\text { Interval } \\
\text { value }\end{array}$ & $\begin{array}{l}\text { Value prior } \\
\text { to discharge }\end{array}$ & $\begin{array}{l}\text { OPD } \\
\text { follow-up }\end{array}$ \\
\hline
\end{tabular}




\section{Cureus}

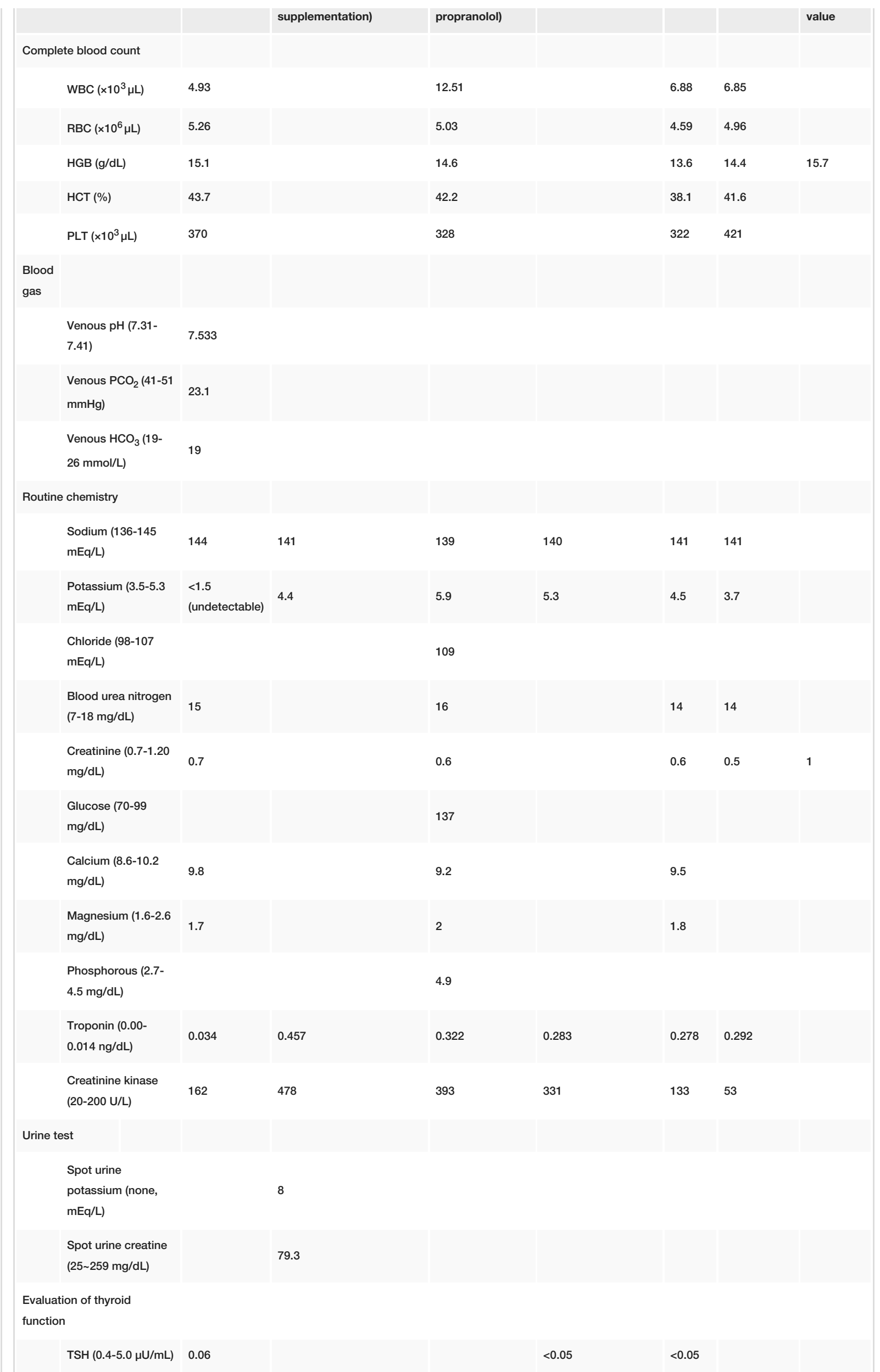




\section{Cureus}

fT4 (0.6-2.3 ng/dL)

$>6.60$

T3 $(60-90 \mathrm{ng} / \mathrm{dL})$

$\operatorname{TRAb}(<15 \%)$
2.97

86

\section{TABLE 1: Initial laboratory results of the patient}

WBC: white blood cell; RBC: red blood cell; HGB: hemoglobin; HCT: hematocrit; PLT: platelet; TSH: thyroid-stimulating hormone; fT4: free thyroxine; T3: triiodothyronine; TRAb: TSH receptor autoantibodies; OPD, outpatient department.

\section{Discussion}

TPP is a rare complication of hyperthyroidism and thyrotoxicosis, which is common in 20- to 40-year-old Asian males. Hot weather, increased exercise, and consumption of large numbers of high-carbohydrate meals and alcoholic drinks are typical causes $[8,9]$. TPP most commonly presents as rapid-onset, transient, symmetrical muscle weakness and fatigue that are associated with hypokalemia [10]. Excessive thyroid hormones can directly alter the cell membrane permeability to potassium by increasing Na+/K+ ATPase activity that induces massive abnormal potassium influx [11]. Hyperthyroidism has also been reported to produce an increased sensitivity to beta-adrenergic stimulation of the gland and an increase in the number of beta-adrenoceptors [12]. This hyperadrenergic state may lead to the activation of the Na+/K+ ATPase, resulting in an increased cellular influx of potassium [13]. Therefore, almost all primary symptoms are related to the change in the potassium level.

Here, we report the presence of rare profound hypokalemia in a patient who was diagnosed with first-time onset of TPP. To investigate how the patient tolerated the severe hypokalemia without experiencing critical symptoms (such as chest pain or altered consciousness), we exhaustively evaluated the patient's medical history and lifestyle habits. Finally, we found that he had a history of chronic alcohol abuse (an 1-L bottle $45 \%-48 \%$ of liquor per week) for more than 10 years. Although in the previous studies of TPP some patients were reported to have a history of alcohol consumption [14-16], but no patients with asymptomatic profound hypokalemia similar to our case were identified. Symptoms of the patient in the previous studies even included chest pain [17]. Thus, we suggest that chronic alcohol abuse may be an important factor that induced chronic hypokalemia.

Hyperthyroidism can induce hyperadrenergic conditions by a chemical structure similar to that of catecholamines, activation of $\mathrm{Na}+\mathrm{K}+$ ATPase, and increase of the sensitivity of $\beta$-receptors $[18,19]$. Moreover, chronic alcoholism is usually associated with electrolyte abnormalities. The causes of hypokalemia in chronic alcoholism include gastrointestinal loss (diarrhea or vomiting), hypomagnesemia, and renal tubular dysfunction [3]. There are few studies of the association between alcohol consumption and thyroid function in individuals who currently actively consume alcohol, because many studies are conducted in detoxification programs. However, the effect of chronic alcohol consumption on hyperthyroidism may be considerable [20]. In this case, chronic alcohol abuse may have increased the patient's tolerance to the profound hypokalemia such that it did not immediately show critical symptoms such as GI symptoms. This might be dangerous for patients because it may delay the diagnosis and crucial medical treatment.

Therefore, according to this case report, we suggest that chronic alcohol consumption or abuse may lead patients, especially those with hyperthyroidism, to ignore or delay treatment.

\section{Conclusions}

Early diagnosis of TPP is important in the case of a patient presenting with hypokalemia and hyperthyroidism. To avoid complications and mortality of TPP in patients with hyperthyroidism, lifestyle changes such as ceasing alcohol consumption should be recommended.

\section{Additional Information}

\section{Disclosures}

Human subjects: Consent was obtained or waived by all participants in this study. Taipei Medical University Hospital Institutional Review Board for Clinical Research issued approval Approval No. N202004067. This study was approved by the Taipei Medical University Hospital Institutional Review Board for Clinical Research (Approval No. N202004067) and it conforms to the provisions of the Declaration of Helsinki. Patient has provided consent for publication of the case. No conflict of interest exists in the submission of this manuscript, and the manuscript is approved by all authors for publication. Conflicts of interest: In compliance with the ICMJE uniform disclosure form, all authors declare the following: 
Payment/services info: All authors have declared that no financial support was received from any organization for the submitted work. Financial relationships: All authors have declared that they have no financial relationships at present or within the previous three years with any organizations that might have an interest in the submitted work. Other relationships: All authors have declared that there are no other relationships or activities that could appear to have influenced the submitted work.

\section{References}

1. De Leo S, Lee SY, Braverman LE: Hyperthyroidism. Lancet. 2016, 388:906-18. 10.1016/S01406736(16)00278-6

2. Ertek S, Cicero AF: Hyperthyroidism and cardiovascular complications: a narrative review on the basis of pathophysiology. Arch Med Sci. 2013, 9:944-52. 10.5114/aoms.2013.38685

3. Elisaf M, Merkouropoulos M, Tsianos EV, Siamopoulos KC: Acid-base and electrolyte abnormalities in alcoholic patients. Miner Electrolyte Metab. 1994, 20:274-81.

4. Paltiel O, Salakhov E, Ronen I, Berg D, Israeli A: Management of severe hypokalemia in hospitalized patients: a study of quality of care based on computerized databases. Arch Intern Med. 2001, 161:1089-95. 10.1001/archinte.161.8.1089

5. Elisaf M, Liberopoulos E, Bairaktari E, Siamopoulos K: Hypokalaemia in alcoholic patients. Drug Alcohol Rev. 2002, 21:73-6. 10.1080/09595230220119282a

6. Kurajoh M, Ohsugi K, Kakutani-Hatayama M, Shoji T, Koyama H: Hypokalemia associated with pseudoCushing's syndrome and magnesium deficiency induced by chronic alcohol abuse. CEN Case Rep. 2018, 7:148-52. 10.1007/s13730-018-0315-4

7. Palmer BF, Clegg DJ: Electrolyte disturbances in patients with chronic alcohol-use disorder . N Engl J Med. 2017, 377:1368-77. 10.1056/NEJMra1704724

8. Darrow M, Brammer WK, Rowley A: Thyrotoxic periodic paralysis: two case studies . Arch Phys Med Rehabil. 1995, 76:685-7. 10.1016/s0003-9993(95)80641-5

9. Neki NS: Hyperthyroid hypokalemic periodic paralysis. Pak J Med Sci. 2016, 32:1051-2. 10.12669/pjms.324.11006

10. Affram KO, Reddy TL, Osei KM: A rare case of thyrotoxic periodic paralysis after epidural steroid injection: a case report and literature review. Am J Case Rep. 2018, 19:1453-8. 10.12659/AJCR.911270

11. Kjeldsen K, Nørgaard A, Gøtzsche CO, Thomassen A, Clausen TT: Effect of thyroid function on number of Na-K pumps in human skeletal muscle. Lancet. 1984, 2:8-10. 10.1016/s0140-6736(84)91996-2

12. Lin SH: Thyrotoxic periodic paralysis. Mayo Clin Proc. 2005, 80:99-105. 10.1016/S0025-6196(11)62965-0

13. Gennari FJ: Hypokalemia. N Engl J Med. 1998, 339:451-8. 10.1056/NEJM199808133390707

14. Tella SH, Kommalapati A: Thyrotoxic periodic paralysis: an underdiagnosed and under-recognized condition. Cureus. 2015, 7:e342. 10.7759/cureus.342

15. Sehmer B, Arnason T: Pop-provoked paralysis: silent Graves' disease presenting as thyrotoxic periodic paralysis. BMJ Case Rep. 2012, 2012:bcr2012006292. 10.1136/bcr-2012-006292

16. Barahona MJ, Vinagre I, Sojo L, Cubero JM, Pérez A: Thyrotoxic periodic paralysis: a case report and literature review. Clin Med Res. 2009, 7:96-8. 10.3121/cmr.2009.816

17. Hagel S, Elznerova T, Dietrich W, Schrauzer T, John S: Chest pain and paralysis after pulse prednisolone therapy an unusual case presentation of thyrotoxic periodic paralysis: a case report. Cases J. 2009, 2:7501. 10.4076/1757-1626-2-7501

18. Levey GS, Klein I: Catecholamine-thyroid hormone interactions and the cardiovascular manifestations of hyperthyroidism. Am J Med. 1990, 88:642-6. 10.1016/0002-9343(90)90533-j

19. Ginsberg AM, Clutter WE, Shah SD, Cryer PE: Triiodothyronine-induced thyrotoxicosis increases mononuclear leukocyte beta-adrenergic receptor density in man. J Clin Invest. 1981, 67:1785-91. 10.1172/jci110218

20. Balhara YP, Deb KS: Impact of alcohol use on thyroid function . Indian J Endocrinol Metab. 2013, 17:580-7. 10.4103/2230-8210.113724 